\title{
The Force Balance of the Southern Ocean Meridional Overturning Circulation
}

\author{
MATTHEW R. MAZLOFF \\ Scripps Institution of Oceanography, La Jolla, California \\ RAFFAELE FERRARI \\ Massachusetts Institute of Technology, Cambridge, Massachusetts \\ TAPIO SCHNEIDER* \\ California Institute of Technology, Pasadena, California
}

(Manuscript received 9 April 2012, in final form 15 February 2013)

\begin{abstract}
The Southern Ocean (SO) limb of the meridional overturning circulation (MOC) is characterized by three vertically stacked cells, each with a transport of about $10 \mathrm{~Sv}\left(\mathrm{~Sv} \equiv 10^{6} \mathrm{~m}^{3} \mathrm{~s}^{-1}\right)$. The buoyancy transport in the SO is dominated by the upper and middle MOC cells, with the middle cell accounting for most of the buoyancy transport across the Antarctic Circumpolar Current. A Southern Ocean state estimate for the years 2005 and 2006 with $1 / 6^{\circ}$ resolution is used to determine the forces balancing this MOC. Diagnosing the zonal momentum budget in density space allows an exact determination of the adiabatic and diapycnal components balancing the thickness-weighted (residual) meridional transport. It is found that, to lowest order, the transport consists of an eddy component, a directly wind-driven component, and a component in balance with mean pressure gradients. Nonvanishing time-mean pressure gradients arise because isopycnal layers intersect topography or the surface in a circumpolar integral, leading to a largely geostrophic MOC even in the latitude band of Drake Passage. It is the geostrophic water mass transport in the surface layer where isopycnals outcrop that accomplishes the poleward buoyancy transport.
\end{abstract}

\section{Introduction}

The Southern Ocean (SO) plays a crucial role in transforming and transporting ocean water masses. The Atlantic, Pacific, and Indian Oceans are connected through the SO, and no description of the global ocean circulation is complete without a full understanding of this region. One wishes to understand the Antarctic Circumpolar Current (ACC) system, the polar gyres, and the meridional overturning circulation (MOC), which are linked as they represent branches of the three-dimensional pathways of ocean water masses. Here we use a synthesis

\footnotetext{
* Current affiliation: Swiss Federal Institute of Technology, Zurich, Switzerland.
}

Corresponding author address: Matthew Mazloff, Scripps Institution of Oceanography, UCSD, Mail Code 0230, 9500 Gilman Drive, La Jolla, CA 92093.

E-mail: mmazloff@ucsd.edu of observations, a numerical model, and theory to investigate the force balance of the SO limb of the MOC.

Standard scaling analysis for the large-scale ocean circulation assumes a small Rossby number, leading to the thermocline equations based on the linearized planetary geostrophic equations (Robinson and Stommel 1959; Welander 1959; Phillips 1963; Pedlosky 1987). But in the Drake Passage latitude band of the SO, at depths where there are no lateral topographic boundaries to support a zonal pressure or buoyancy gradient, nonlinear eddy terms become important: one can show that below the surface Ekman and diabatic layers and above any bottom boundary layers, the planetary geostrophic equations, ignoring eddy fluxes of buoyancy and momentum, would imply constant vertical velocities, $\bar{w}=$ $\bar{w}_{\mathrm{Ek}}=f \partial_{y} \bar{\tau}^{x}$, and no stratification, $\partial_{z} \bar{b}=0$ (Samelson 1999). Here $f$ is the Coriolis parameter, $w$ is the vertical velocity, $\tau^{x}$ is the zonal wind stress, and $b$ is the buoyancy. We denote zonal and temporal means with overbars; fluctuations about them will be denoted by primes. 
Therefore, the unblocked latitudes of the SO would be unstratified, and, for $\partial_{y} \bar{\tau}^{x}>0$, would have an overturning circulation that is clockwise when south is plotted on the left; it would consist of an equatorward Ekman transport near the surface balanced by poleward transport in the abyss $\left(\bar{\psi}=\int w d y=f \bar{\tau}^{x}\right){ }^{1}$ This is contrary to observations, which show significant stratification in the unblocked latitudes and demand a poleward heat transport that cannot be achieved with surface waters flowing equatorward (Mazloff et al. 2010).

The counterclockwise, thermally direct overturning circulation demanded by observations can be understood by realizing that tracers in the mean are not advected by the Eulerian mean circulation, but by a Lagrangian mean circulation (Wüst 1935). Andrews and McIntyre (1976) showed that the Lagrangian mean circulation of nearly conservative tracers in quasigeostrophic flows is well approximated by the sum of the Eulerian mean circulation $\bar{\psi}$ and an eddy-induced circulation

$$
\psi_{e}=\frac{\overline{v^{\prime} b^{\prime}}}{\partial_{z} \bar{b}},
$$

which represents a Stokes drift associated with the meridional eddy fluxes. The sum of the two velocities is referred to as the residual velocity,

$$
\left(\bar{v}_{\text {res }}, \bar{w}_{\text {res }}\right)=(\bar{v}, \bar{w})+\left(v_{e}, w_{e}\right),
$$

where $\left(v_{e}, w_{e}\right)=\left(-\partial_{z}, \partial_{y}\right) \psi_{e}$. Thus eddy fluxes contribute to the mean transport, and models that do not resolve these eddies must parameterize them (Treguier et al. 1997).

A full theory of the SO in the unblocked latitude band must account for the residual circulation in addition to the Eulerian mean overturning. The planetary geostrophic equations for the residual circulation in the unblocked latitudes and above topography take the form

$$
\begin{aligned}
-f \bar{v}_{\text {res }} & =\partial_{z} \bar{\tau}^{x}+f \partial_{z}\left(\frac{\overline{v^{\prime} b^{\prime}}}{\partial_{z} \bar{b}}\right), \\
f \partial_{z} \bar{u} & =\partial_{z z} \bar{\tau}^{y}-\partial_{y} \bar{b} \\
\partial_{y} \bar{v}_{\text {res }}+\partial_{z} \bar{w}_{\text {res }} & =0,
\end{aligned}
$$

\footnotetext{
${ }^{1}$ Throughout this paper, we use the south to north plotting convention, such that a clockwise overturning cell consists of northward flow of relatively buoyant waters and southward flow of less buoyant waters. In the SO, a clockwise overturning is thermally indirect, as it transports buoyancy upgradient toward the equator.
}

$$
\bar{v}_{\text {res }} \partial_{y} \bar{b}+\bar{w}_{\text {res }} \partial_{z} \bar{b}=-\nabla \cdot \mathcal{B},
$$

where $-\nabla \cdot \mathcal{B}$ is the diabatic buoyancy forcing. These equations support an interior stratification where $\nabla \cdot \mathcal{B}$ is weak as long as there is an eddy flux that drives $\bar{v}_{\text {res }}$ in the zonal momentum equation. The buoyancy budget shows that, if the diabatic forcing is weak, the residual circulation must be along mean density (buoyancy) surfaces.

Marshall and Radko (2003) used Eqs. (1)-(4) to construct a model of the overturning circulation of the SO. Their model offers useful insights into the dynamics of unblocked zonal flows. Questions remain, however, whether this and similar models are quantitatively accurate because the solution is determined by the boundary conditions at the surface, where the quasigeostrophic approximations used to derive the planetary geostrophic equations for the residual circulation do not apply. Held and Schneider (1999), Schneider et al. (2003), and Schneider (2005) showed that nonquasigeostrophic effects at the boundaries (specifically, relatively large isopycnal slopes) modify the overall residual circulation of the atmosphere. Similar issues may arise in the ocean.

Plumb and Ferrari (2005) extended the planetary geostrophic system in (1)-(4) to account for nonquasigeostrophic effects. However, their momentum and buoyancy equations involve terms that are difficult to diagnose from observations or numerical models. For example, their equations involve terms like $\overline{v^{\prime} b^{\prime}} / \partial_{z} \bar{b}$ and $\overline{w^{\prime} b^{\prime}} / \partial_{y} \bar{b}$, which are poorly defined in regions of weak stratification (e.g., in the surface layer). Averaging the planetary geostrophic equations at fixed density, instead of fixed depth, allows one to directly diagnose the diapycnal and adiabatic fluxes, without approximations. In the next section, we formulate the full zonal momentum budget in isopycnal coordinates. The equations are similar to those derived by Schneider (2005) for the atmosphere, but some additional complications arise in the ocean owing to the presence of lateral boundaries and the nonlinearity of the equation of state.

A second limitation of the reentrant channel model described by (1)-(4) is that it ignores the remote forcing of the ACC by the subtropical and polar gyres abutting it. Gill (1968) showed that, even though the ACC may be governed by channel dynamics, a full theory of its transport requires specification of the northern and southern inflow and outflow conditions. A complete understanding of the ACC circulation cannot be attained solely with either Sverdrupian models of gyre circulations or channel models, but requires a merging of the two approaches, as attempted in some recent theories (Nadeau and Straub 2009; LaCasce and Isachsen 2010; Nikurashin and Vallis 2011; Nadeau and Straub 2012; Nikurashin and Vallis 2012). 
In this study, we address these issues by diagnosing the momentum and buoyancy budgets of the SO from a model that is fit to observations and in which eddies and their associated transports are explicitly represented. Our primary analysis tool is a Southern Ocean state estimate (SOSE) for the years 2005 and 2006 (Mazloff et al. 2010). ${ }^{2}$ The ocean state is estimated with a general circulation model run at $1 / 6^{\circ}$ resolution and optimized to match observations in a weighted least squares sense. Convergence to the state estimate is achieved by systematically adjusting the atmospheric driving and initial conditions using an adjoint model. A cost function compares the model state to in situ observations (Argo float profiles, CTD synoptic sections, seal-mounted SEaOS instrument profiles, and XBTs), altimetric observations [Envisat, Geosat, Jason, Ocean Topography Experiment (TOPEX)/Poseidon)], and other datasets (e.g., sea surface temperatures inferred from infrared and microwave radiometers). In contrast to other data assimilation approaches, no spurious nudging terms are introduced in the dynamical equations, and therefore the state estimate represents a physically sound solution that satisfies the discretized equations of motion of the model. Mazloff (2008) describes in detail the assimilation procedure and the observations used. SOSE is a good resource for quantifying the dynamical balances in question because it has eddy kinetic energy on par with that observed, it is largely consistent with individual observations, and it is consistent with integrated fluxes inferred from previous static inverse models (Mazloff et al. 2010).

The primary focus of this paper is on the thermally indirect SO MOC cell that upwells deep waters in the Drake Passage latitude band and returns intermediate waters to ventilate the thermoclines of the subtropical gyres. This is often referred to as the upper SO MOC cell, but because our study region extends into the subtropics where there is an even shallower thermocline, with an additional MOC cell, we here refer to this as the middle MOC cell. The overall goal is to assess the relative importance of eddies and mechanical wind forcing in driving the circulations and to understand how the MOC in the ACC latitude band merges with the gyroscopic flows north and south of it.

The paper is organized as follows. In section 2, the mass and zonal momentum budgets are formulated in

\footnotetext{
${ }^{2}$ As part of the Antarctic Treaty, the International Hydrographic Organization has defined the Southern Ocean to extend from $60^{\circ} \mathrm{S}$ to Antarctica. The region of study in this work is the oceans south of $25^{\circ} \mathrm{S}$, which, for ease, will be referred to collectively as the Southern Ocean.
}

isopycnal coordinates to illuminate the different factors contributing to the dynamical balance of the MOC. SOSE output is used to diagnose the MOC in section 3 and the terms in the zonal momentum budget in section 4. A synthesis of the dominant dynamical balance of the MOC is presented in section 5, and implications for models of the MOC are discussed in section 6.

\section{Mass and zonal momentum budget in isopycnal coordinates}

In this section, the mass and zonal momentum budgets are formulated in neutral density coordinates, assuming that the ocean is stably stratified (see Vallis 2006, section 3.9 for a derivation). Neutral density $\gamma$, which largely removes the effects of compressibility from in situ density (Jackett and McDougall 1997), is used as the vertical coordinate. Surfaces of constant $\gamma$ will be referred to as isopycnals.

The continuity equation in isopycnal coordinates takes the form,

$$
\partial_{t} h+\partial_{x}(h u)+\partial_{y}(h v)+\partial_{\gamma}(h Q)=0,
$$

where $h=\rho_{0} \partial_{\gamma} z$ is the "thickness" of isopycnal layers ( $z$ is their height), $\rho_{0}$ is a constant reference density, $(u, v)$ is the horizontal velocity, and $Q=D \gamma / D t$ the material density tendency (diapycnal "velocity"). Horizontal and time derivatives are understood as taken at constant neutral density. Taking an average over long times and along a latitude circle gives

$$
\partial_{t} \bar{h}+\partial_{y}\left(\bar{h} \bar{v}^{*}\right)+\partial_{\gamma}\left(\bar{h} \bar{Q}^{*}\right) \approx 0,
$$

where the averaging convention used is to set the argument to zero when isopycnals vanish. We denote thicknessweighted averages by $\overline{(\cdot)}^{*}=\overline{(h \cdot)} / \bar{h}$.

The meridional residual velocity $\bar{v}_{\text {res }}$ is an approximation in $z$ coordinates of the thickness-weighted meridional velocity $\bar{v}^{*}$ on isopycnals (Andrews et al. 1987; Juckes et al. 1994; McIntosh and McDougall 1996; McDougall and McIntosh 1996; Nurser and Lee 2004). Like the residual meridional velocity $\bar{v}_{\text {res }}$, the velocity $\bar{v}^{*}$ includes an Eulerian mean contribution and an eddy contribution owing to correlations between meridional velocities and thickness variations [see Andrews et al. (1987) and Nurser and Lee (2004) for a discussion of the analogy between residual circulations and thicknessweighted circulations in isopycnal coordinates]. A main advantage of working in isopycnal coordinates is that the thickness-weighted circulation appears naturally in the averaged equations and is easily diagnosed. 
The zonal momentum budget at fixed $\gamma$ can be written as

$\partial_{t} u+\frac{1}{2} \partial_{x}\left(u^{2}+v^{2}\right)+Q \partial_{\gamma} u-(f+\zeta) v=-\rho_{0}^{-1}\left(\mathcal{P}^{x}-F\right)$,

where $\zeta \equiv v_{x}-u_{y}$ is the relative vorticity of the fluid and $F$ accounts for all mechanical forcing and viscous effects. The pressure gradient in isopycnal coordinates is $\mathcal{P}^{x}=\partial_{x} p+g \rho \partial_{x} z$, with pressure $p$, gravitational acceleration $g$, and in situ density $\rho .^{3}$ In the Boussinesq approximation, this reduces to the $x$ derivative of the Montgomery potential, $\mathcal{P}_{x} \approx \partial_{x} \mathcal{M}=\partial_{x}\left(p+g \rho_{0} z\right)$. Here we keep the general form that accounts for compressibility effects.

The zonal momentum budget (7) is now averaged zonally along a latitude circle and over a long time,

$\overline{\partial_{t} u}+\frac{1}{2} \overline{\partial_{x}\left(u^{2}+v^{2}\right)}+\overline{Q \partial_{\gamma} u}-\overline{h v q}=-\rho_{0}^{-1}\left(\overline{\mathcal{P}^{x}}-\bar{F}\right)$,

where $q \equiv(f+\zeta) / h$ is the Rossby-Ertel potential vorticity $(\mathrm{PV})$.

The meridional PV flux $\overline{h v q}=\bar{h} \overline{v q}$ * plays a crucial role in the zonal momentum budget. It is useful to decompose it into mean and eddy components. Using the thickness-weighted mean, we split flow fields $(\cdot)$ into mean $\overline{(\cdot)}^{*}$ and eddy components $\widehat{(\cdot)}=(\cdot)-\overline{(\cdot)}^{*}$, such that, for example, $q=\bar{q}^{*}+\hat{q}$ and $v=\bar{v}^{*}+\hat{v}$ (Favre decomposition). If we neglect cross terms (i.e., $\overline{\hat{v} \bar{q}^{* *}}={\overline{v^{*}}}^{*}{ }^{*}=0$ ), the PV flux becomes

$$
\bar{v}^{*} \equiv \bar{v}^{*} \bar{q}^{*}+\overline{\hat{v}}^{*}
$$

and Eq. (8) can be written as

$$
\begin{aligned}
\overline{\partial_{t} u} & +\frac{1}{2} \overline{\partial_{x}\left(u^{2}+v^{2}\right)}+\overline{Q \partial_{\gamma} u}-\bar{h} \bar{v}^{*} \bar{q}^{*}-\bar{h} \overline{\hat{v} \hat{q}^{*}} \\
& =-\rho_{0}^{-1}\left(\overline{\mathcal{P}^{x}}-\bar{F}\right) .
\end{aligned}
$$

If the momentum budget reaches a statistically steady state such that $\overline{\partial_{t} u} \approx 0$, then (10) can be used to diagnose what balances the thickness-weighted average meridional circulation $\bar{h} \bar{v}^{*}$. This is the main goal of the paper.

\footnotetext{
${ }^{3}$ When converting from $z$ coordinates to $\gamma$ coordinates, the pressure gradient term becomes $\left.\partial_{x} p\right|_{z}=\left.\partial_{x} p\right|_{\gamma}-\left.\left.\partial_{x} z\right|_{\gamma} \partial_{x} p\right|_{\gamma} \partial_{z} p=$ $\left.\partial_{x} p\right|_{\gamma}+\left.g \rho \partial_{x} p\right|_{\gamma}$, where the hydrostatic relation, $\partial_{x} p=-g \rho$, has been used.
}

\section{a. Mean potential vorticity at outcrops}

The thickness-weighted mean potential vorticity $\bar{q}^{*}$ contains the expression $\overline{h(f+\zeta) / h}$, which is indefinite where $h=0$ (at outcrops). Koh and Plumb (2004) suggest to interrupt the zonal averaging in those regions without adjusting the normalization of the averages by still dividing by the full length of the latitude circle and duration of the averaging period, which corresponds to setting $\overline{h(f+\zeta) / h}=0$, where $h=0$. This approach is followed here, and the reader is referred to Schneider (2005) and Jansen and Ferrari (2013, manuscript submitted to J. Atmos. Sci.) for a discussion of alternative approaches.

\section{b. Mean pressure gradient at outcrops}

The zonal average of the pressure gradient term contributes differently in $z$ and $\gamma$ coordinates. In $z$ coordinates, the zonal average reduces to the sum of pressure differences across topographic features. In $\gamma$ coordinates, in the Boussinesq approximation, the zonal average reduces to the sum of the Montgomery potential difference across both topographic features and density outcrops. Consider the Montgomery potential integrated over a layer bounded by the free surface on top and by a submerged isopycnal $\gamma_{n}$ at the bottom. In the Boussinesq approximation, we have

$$
\begin{aligned}
\int_{\gamma_{n}}^{\gamma_{\text {surf }}} \mathcal{P}^{x} d \gamma & \approx \int_{\gamma_{n}}^{\gamma_{\text {surf }}} \partial_{x} \mathcal{M} d \gamma=\int_{\gamma_{n}}^{\gamma_{\text {surf }}} \partial_{x}\left(p+g \rho_{0} z\right) d \gamma \\
& =\partial_{x} \int_{\gamma_{n}}^{\gamma_{\text {surf }}}\left(p+g \rho_{0} z\right) d \gamma-g \rho_{0} \eta \partial_{x} \gamma_{\text {surf }}
\end{aligned}
$$

where $\gamma_{\text {surf }}$ is the density at the free surface of the ocean and we substituted $z=\eta$ and $p=0$ at this free surface. Taking the zonal average of (11) and assuming there are no lateral boundaries, we obtain

$$
\overline{\int_{\gamma_{n}}^{\gamma_{\text {surf }}} \partial_{x} \mathcal{M} d \gamma}=-g \rho_{0} \overline{\eta \partial_{x} \gamma_{\text {surf }}} s,
$$

where $\overline{(\cdot)}^{s}$ is an average along the surface. This "force" exerted at outcropping isopycnals $\gamma_{\text {surf }}$ is proportional to the correlations between the Montgomery potential and isopycnal slope at the surface. It is analogous to the form drag in $z$ coordinates that results from correlations between pressure and topographic slope (Andrews 1983).

More insight into the role of form drag at outcrops is obtained by integrating (12) by parts and using the definition of geostrophic velocity at the surface $v_{g}=f^{-1} g \partial_{x} \eta$ :

$$
\overline{\int_{\gamma_{n}}^{\gamma_{\text {surf }}} \partial_{x} \mathcal{M} d \gamma}=f \rho_{0} \overline{v_{g} \gamma_{\text {surf }}} s .
$$




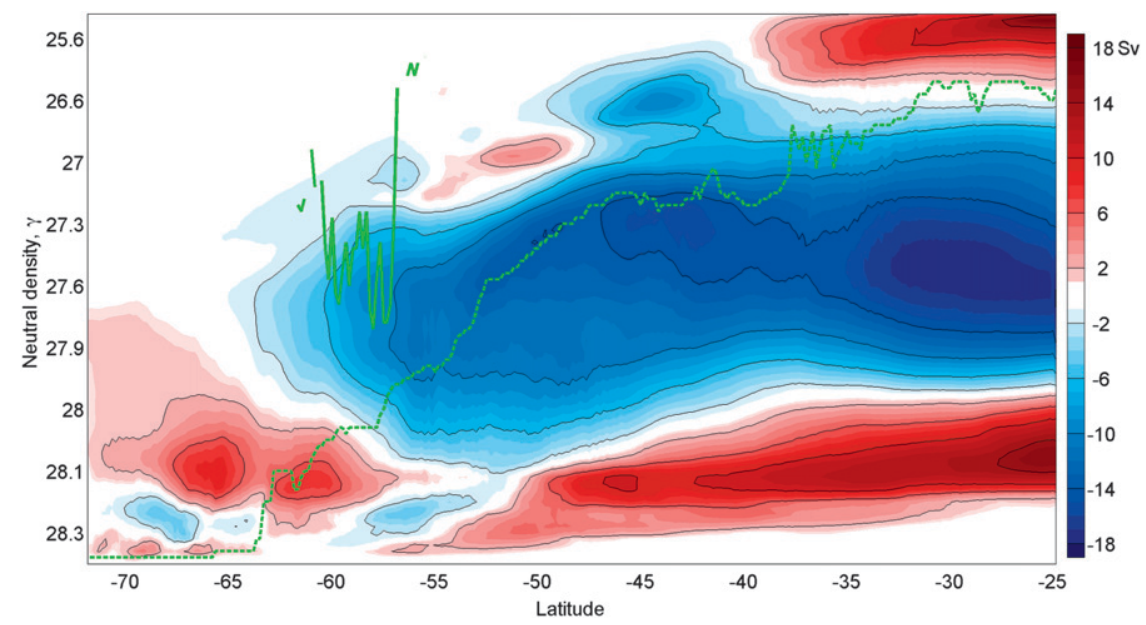

FIG. 1. Southern Ocean overturning streamfunction $\psi^{*}$ plotted in neutral density $(\gamma)$ coordinates. The plotting convention is to multiply the zonally averaged terms by latitude circle length to determine transport in Sverdrups. The contour interval for the black contours is $4 \mathrm{~Sv}$. Positive (negative) values denote counterclockwise (clockwise) circulations. Vertical components of streamlines denote movement across isopycnals and thus diabatic processes. Here and in subsequent figures, the upper solid green line denotes topography; isopycnals above this line never outcrop into land. The lower green-dashed line denotes the bottom of the surface layer; isopycnals below this line never outcrop at the surface. The density axis is stretched by a factor that reflects the volume of water at each density class (i.e., approximately the same value of water is found between each $\gamma$ tick mark).

The surface form drag is proportional to the geostrophic meridional density flux, as derived in the atmospheric context by Andrews (1983) and Schneider (2005). Thus, even if there are no lateral boundaries, a mean Montgomery potential gradient can exist in the surface layer owing to correlations between velocity and density fluctuations. An equivalent bottom form drag results from interactions of isopycnals with the ocean bottom.

\section{Meridional overturning circulation of the Southern Ocean}

The goal of this paper is to understand the dominant balance of forces in the SO MOC. The first step is to diagnose the MOC streamfunction, which in neutral density coordinates is given by the volume transport between the ocean bottom and a neutral density surface $\gamma$ :

$$
\psi^{*}(y, \gamma)=\rho_{0}^{-1} \overline{\int_{\gamma_{b}}^{\gamma} h v d \gamma},
$$

with $\gamma_{b}$ the neutral density at the ocean bottom. Temporally averaging the streamfunction over the two years of the state estimate, Fig. 1, shows the MOC to be characterized by three primary cells, each with a transport of about $10 \mathrm{~Sv}\left(\mathrm{~Sv} \equiv 10^{6} \mathrm{~m}^{3} \mathrm{~s}^{-1}\right)$. The upper overturning cell, which is part of the horizontal subtropical gyres, rotates counterclockwise and is confined to the lightest density classes, all of which outcrop somewhere along the latitude circle. This cell consists of a poleward surface flow compensated by an equatorward interior return flow of Antarctic Intermediate Water (AAIW) and Antarctic Mode Water (AMW). The middle cell rotates clockwise and consists of Upper Circumpolar Deep Water (UCDW) flowing into the SO at depth and a return flow of AAIW. The abyssal cell rotates counterclockwise and consists of inflowing Lower Circumpolar Deep Water (LCDW) and an abyssal outflow of Antarctic Bottom Water (AABW).

The MOC undergoes a substantial seasonal cycle in the SO, as also found by Wunsch and Heimbach (2009). In Fig. 2, the MOC is shown separately for each season, that is, time averaging for two years over threemonth windows: December-February (austral summer), March-May (fall), June-August (winter), and SeptemberNovember (spring). The intermediate cell exhibits large seasonal shifts, with its transport becoming quite weak across $\sim 40^{\circ} \mathrm{S}$ in summer and fall and increasing to over $20 \mathrm{~Sv}$ in the spring and winter. The greatest seasonal change occurs in the upper cell, which is strong ( $\sim 10 \mathrm{~Sv})$ in spring and winter and almost nonexistent poleward of $40^{\circ} \mathrm{S}$ in summer and fall.

The strong seasonal variability in the MOC raises the question of whether $\psi^{*}$ can be interpreted as 



FIG. 2. Southern Ocean overturning streamfunction $\psi^{*}$ for each austral season: (a) spring (September-November); (b) summer (December-February); (c) fall (March-May); and (d) winter (June-August). As in Fig. 1, positive (negative) values denote counterclockwise (clockwise) circulations, and the zonally averaged terms are multiplied by latitude circle length to determine transport in Sverdrups. Green lines indicate outcroppings (though now relevant to each season), and the density axis is stretched.

a streamfunction tracking the pathways of water masses: $\psi^{*}$ is a streamfunction only if the mass budget is approximately in a statistically steady state over the time interval considered. As given by (6), the temporal and zonal mean of the continuity equation is $\partial_{y}\left(\bar{h} \bar{v}^{*}\right)=$ $-\partial_{t} \bar{h}-\partial_{\gamma}\left(\bar{h} \bar{Q}^{*}\right)$. The two terms on the right-hand side of this equation represent the processes that drive meridional transport: a change in the ocean stratification through heat or freshwater storage in the ocean (first term) and diabatic forcing in the form of irreversible mixing in the ocean interior and air-sea fluxes at the ocean surface (second term). In the abyssal cell there are a few latitude bands where the volume flux is largely balanced by changes in the volume of the density layer, $\partial_{t} \bar{h}$. These occur predominantly between $45^{\circ}$ and $65^{\circ} \mathrm{S}$ on isopycnals with density greater than $\gamma=$ $27.8 \mathrm{~kg} \mathrm{~m}^{-3}$, and most significantly in fall. What appears to be a closed abyssal cell in the circulation is actually a change in the volume of the isopycnal layer. This is likely a model drift that would be eliminated by averaging over a longer time period. The upper two MOC cells are in statistically steady state, however, as the thickness tendency $\partial_{t} \bar{h}$ is negligible both over the two full years and over individual seasons. Therefore, $\psi^{*}$ can be interpreted as a streamfunction in the upper cells.

The primary focus in this paper is on the middle cell, as this cell dominates the buoyancy budget in the ACC latitudes (Fig. 3). There is, however, a small compensating poleward transport of buoyancy from the upper cell especially in spring and winter. The middle MOC cell vanishes near the subtropical front in fall and summer because the subduction of waters into the ocean interior is stalled as surface waters become very buoyant. The upper cell is part of the subtropical gyres and dominates the total poleward buoyancy transport in the subtropics from spring to fall, with a middle cell contribution in winter. In the polar regions, the abyssal MOC cell controls the relatively small poleward buoyancy transport, as it is the only overturning cell at those latitudes. Its contribution to buoyancy transport becomes insignificant north of the polar front because the difference in buoyancy between LCDW and AABW is small. In summary, the overall buoyancy transport in the SO is dominated by the upper and middle MOC cells, with the middle cell accounting for most the buoyancy transport across the ACC. We now diagnose the forces balancing this transport.

\section{Force balance of the Southern Ocean meridional overturning circulation}

A detailed quantification of the forces that balance the three MOC cells can be achieved through the temporal and zonal mean momentum budget in (10). This analysis is presented below for the winter and summer seasons 

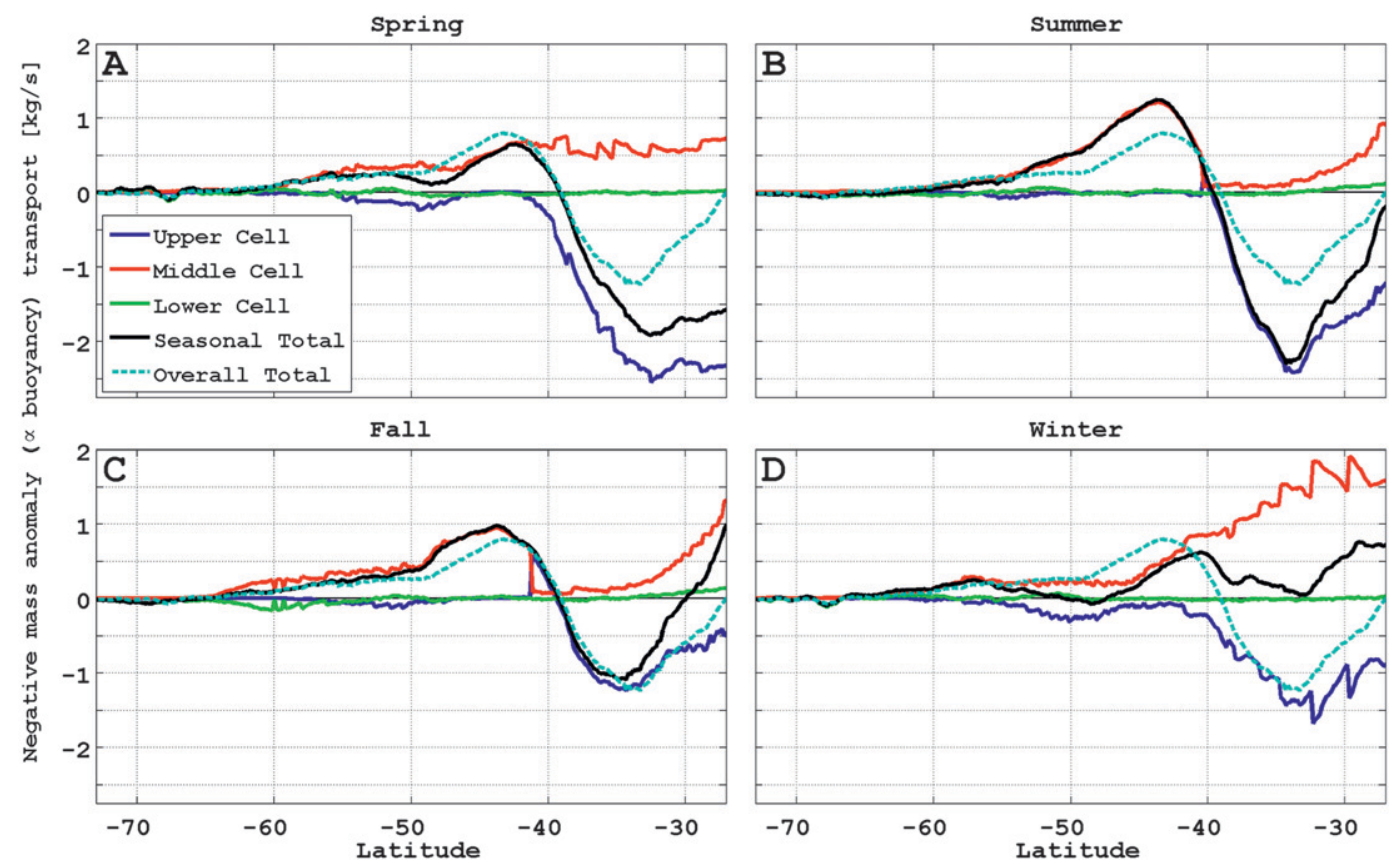

FIG. 3. Buoyancy transport $\int \psi d b\left(\mathrm{~kg} \mathrm{~s}^{-1}\right)$ of the overturning cells in Fig. 2. Positive (negative) values denote equatorward (poleward) buoyancy transport.

only because the winter/spring and summer/fall budgets are very similar, as can be inferred from Fig. 2. The dominant terms in the momentum budget are $\bar{h} \bar{v} q^{*}$, $-\rho_{0}^{-1} \overline{\mathcal{P}^{x}}$, and $\rho_{0}^{-1} \bar{F}$; the residual of these dominant terms is relatively small, showing that the other terms in (10) can be dropped from the budget (Figs. 4 and 5). We verified that the acceleration term $\bar{u}_{t}$ is always less than $10 \%$ of the dominant terms. Hence, the momentum budget can be considered in a statistically steady state to within $10 \%$. This does not imply that the momentum
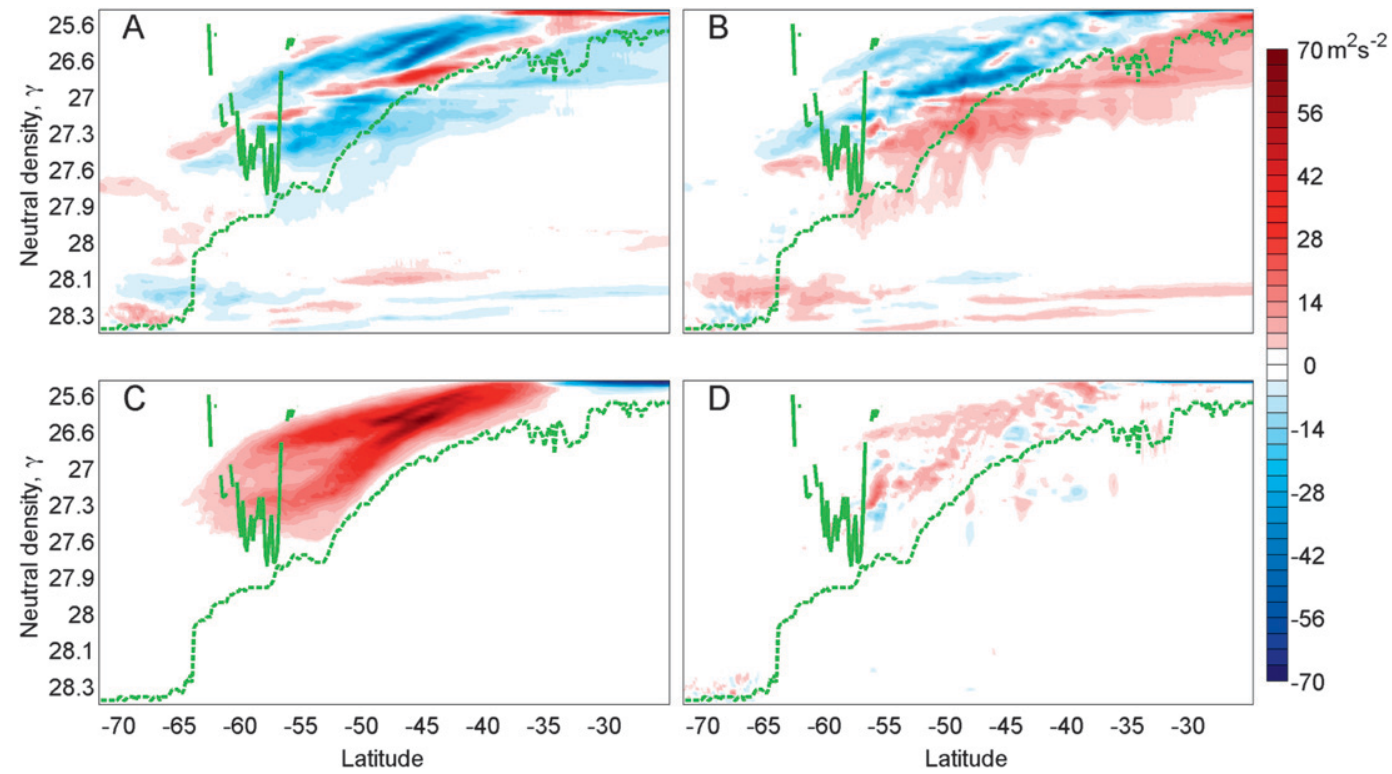

FIG. 4. Dominant terms in Eq. (10) in austral summer: (a) $\bar{h} \overline{v q}^{*},(\mathrm{~b})-\rho_{0}^{-1} \overline{\mathcal{P}^{x}}$, (c) $\rho_{0}^{-1} \overline{\mathcal{F}^{x}}$, and (d) the residual of these three terms. These zonally averaged terms are multiplied by latitude circle length in keeping with the plotting convention. Units are $\mathrm{m}^{2} \mathrm{~s}^{-2}$. 

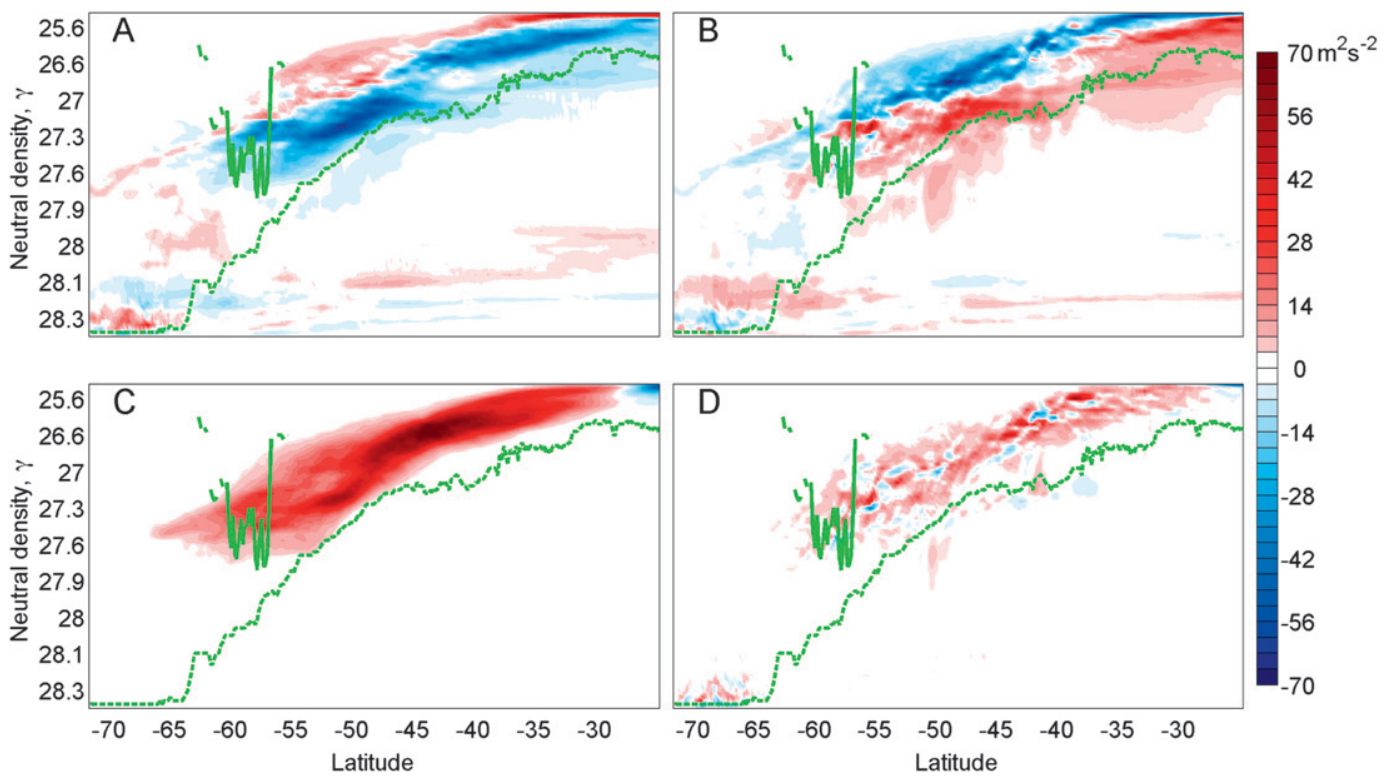

FIG. 5. As in Fig 4, but in austral winter.

budget remains unchanged across seasons (Fig. 2) or that there are no drifts in stratification (section 3); it simply means that accelerations are small during those variations. We also found that the diapycnal momentum flux $\overline{Q \partial_{\gamma} u}$ and the nonlinear term $\overline{\partial_{x}\left(u^{2}+v^{2}\right)}$ are $10 \%$ or less of the dominant terms. Neglecting these second-order terms, the momentum budget (10) can be rearranged to decompose the volume transport within a density layer,

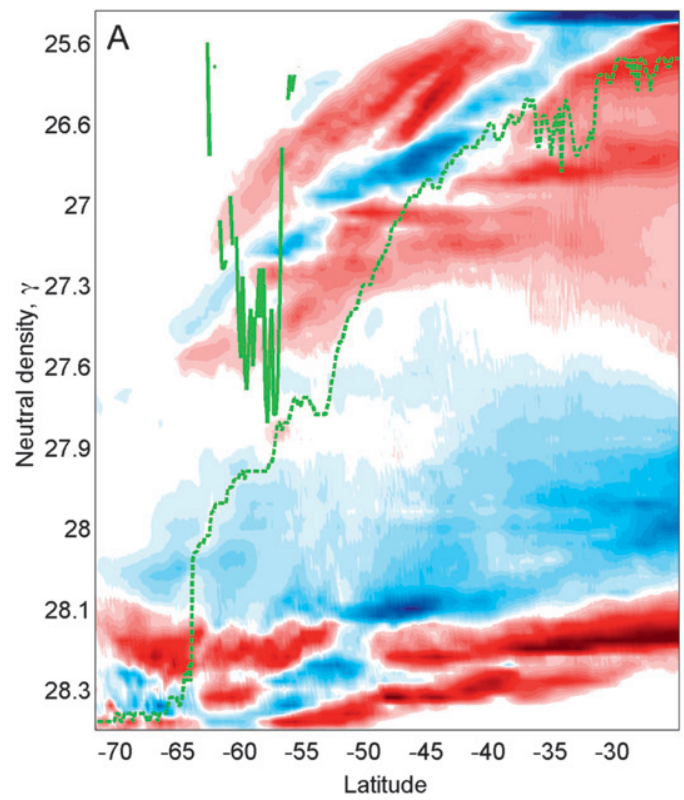

$$
\bar{h} \bar{v}^{*} \approx\left(\bar{q}^{*}\right)^{-1}\left[-\bar{h} \overline{\hat{v}}^{*}+\rho_{0}^{-1}\left(\overline{\mathcal{P}^{x}}-\bar{F}\right)\right] .
$$

Thus the volume transport in each layer, $\bar{h} \bar{v}^{*}$, which is shown in Fig. 6, is composed of an eddy component associated with potential vorticity fluxes, a mean geostrophic component associated with mean pressure gradients, $f \bar{v}_{g}=\rho_{0}^{-1} \overline{\mathcal{P}^{x}}$, and a mean Ekman component driven by mean mechanical stresses, $f \bar{v}_{\mathrm{Ek}}=-\rho_{0}^{-1} \bar{F}$. A physical interpretation of these terms is presented in

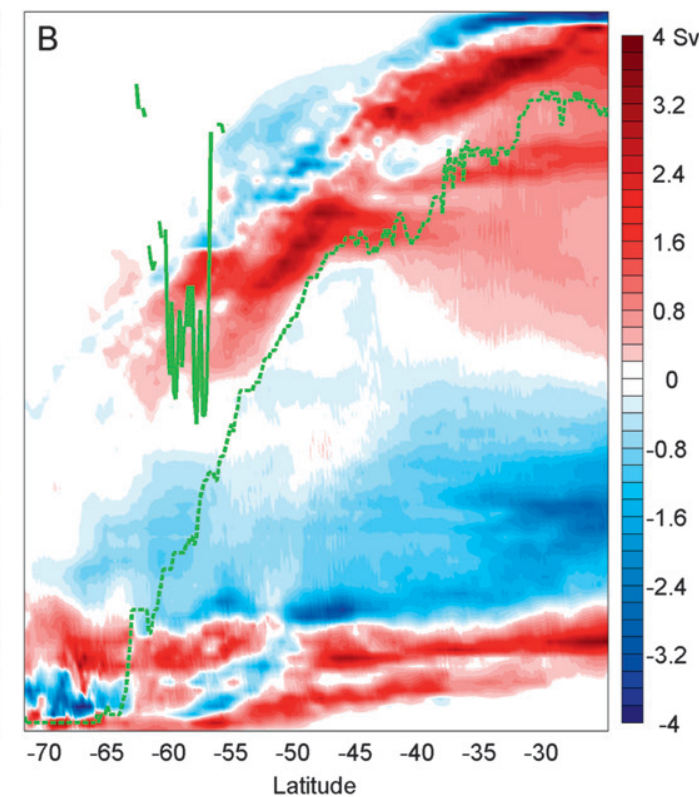

FIG. 6. Austral (a) summer and (b) winter meridional volume transport (Sv): positive (negative) values denote northward (southward) transport. 

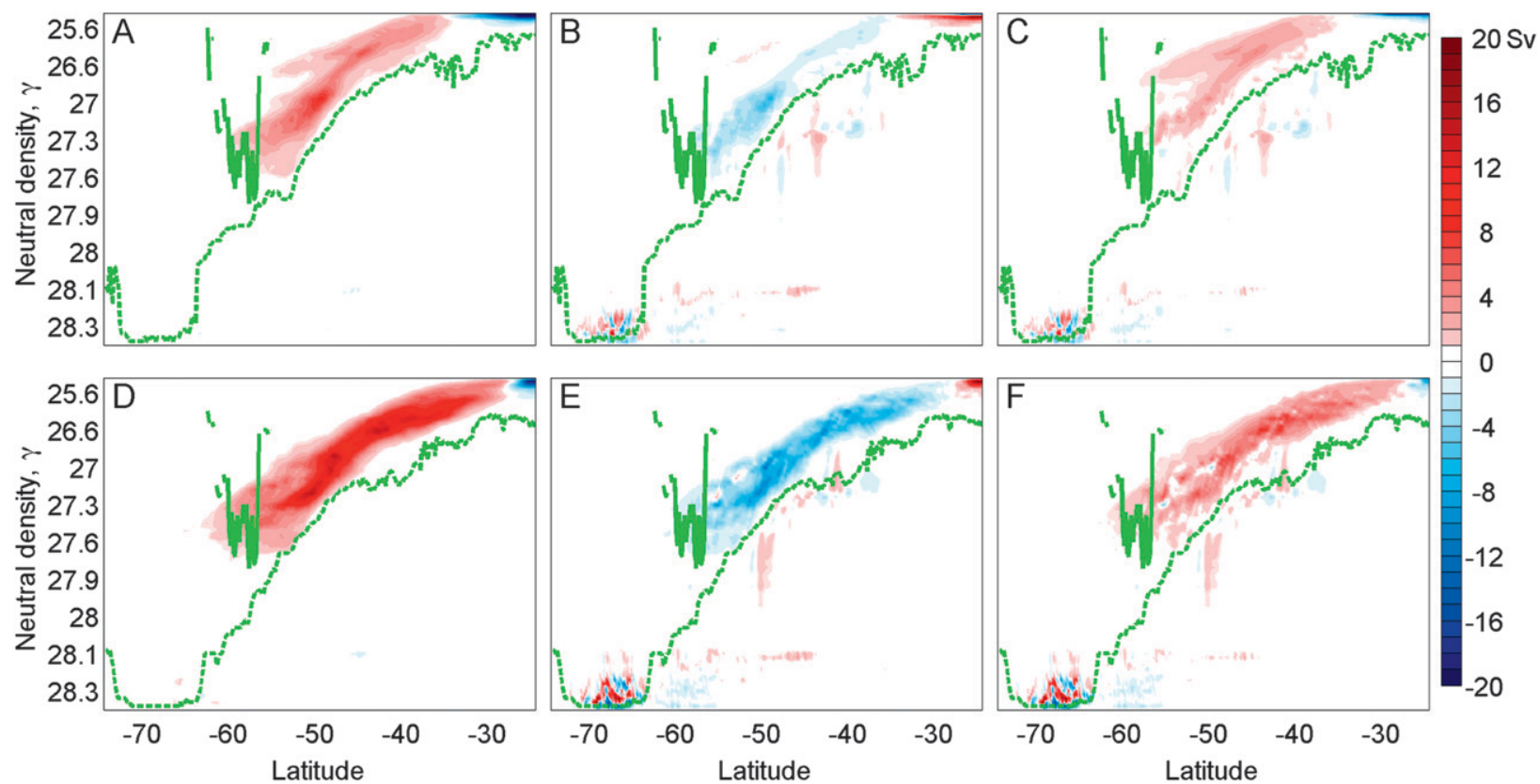

FIG. 7. Components of the meridional volume transport (Sv) associated with (a),(d) mean mechanical and viscous forcing $\left(\bar{q}^{*}\right)^{-1} f \bar{v}_{\mathrm{Ek}}=-\left(\rho_{0} \bar{q}^{*}\right)^{-1} \bar{F} ;(\mathrm{b}),(\mathrm{e})$ ageostrophic eddy potential vorticity fluxes $-\bar{h}\left(\bar{q}^{*}\right)^{-1} \overline{\hat{v}}_{a} \hat{q}^{*} ;$ and (c),(f) the sum of the two giving the total Ekman transport. (top) Austral summer and (bottom) austral winter are represented.

what follows. In section 5 , we show how these terms are collectively organized to balance the SO MOC of Fig. 2.

\section{a. Mean wind stress}

The volume transport driven by mean wind stresses is given by $\left(\bar{q}^{*}\right)^{-1} f \bar{v}_{\text {Ek }}$. As expected, wind stresses drive the most buoyant waters equatorward (Figs. 7a,d). A bimodal distribution of surface densities on latitude circles creates a transport bifurcation poleward of $48^{\circ} \mathrm{S}$, and this is especially noticeable in summer. The mean wind stresses are much larger in austral winter.

The cumulative magnitude of this mean wind transport is stronger than the $\sim 30 \mathrm{~Sv}$ of mean Ekman flow previously reported in $z$ coordinate calculations (e.g., Mazloff et al. 2010). This difference is due to the $\gamma$ coordinate calculation; there are strong $\gamma$ fluctuations at the surface causing the wind transport to be partitioned between the zonally averaged frictional forcing and the eddy PV flux as shown in the next section.

\section{b. Ageostrophic eddy transport}

We split the eddy PV flux into geostrophic and ageostrophic components:

$$
\overline{\hat{v}}^{*}=\overline{\hat{v}}_{a} \hat{q}^{*}+\overline{\hat{v}}_{g} \hat{q}^{*}
$$

where the ageostrophic velocity is defined as the residual, $v_{a}=v-v_{g}$. There are ageostrophic velocities in the densest layers; however, the ageostrophic eddy PV flux $\overline{\hat{v}}_{a} \hat{q}^{*}$ acts primarily on the most buoyant surface flows (Figs. 7b,e). The wind-driven Ekman velocity dominates $v_{a}$ such that $v_{a} \approx v_{\mathrm{Ek}}=-\left(\rho_{0} f\right)^{-1} F$; additional ageostrophic transports are minimal even in the boundary layers (Mazloff et al. 2010). Thus, the wind contributes to the meridional volume transport through two different terms in (14). The first contribution, arising from $\bar{F}$, represents the wind-driven transport by the zonally and temporally averaged Ekman velocity, $\bar{v}_{\mathrm{Ek}}$; the second contribution, associated with ageostrophic eddy fluxes, $\overline{\hat{v}}_{a} \hat{q}^{*} \approx \overline{\hat{v}}_{\mathrm{Ek}} \hat{q}^{*}$, is the transport driven by Ekman fluctuations. Notice that fluctuations are defined with respect to averages along density surfaces, and they are particularly large in the upper ocean where density surfaces undergo significant excursions driven by changes in buoyancy fluxes.

It is enlightening to combine the mean and eddy Ekman transports. Making use of the identity $\overline{\hat{v}}_{\mathrm{Ek}} \hat{q}^{*}=$ $\overline{v_{\mathrm{Ek}}} q^{*}-\overline{v_{\mathrm{Ek}}} \bar{q}^{*}$ and of the fact that Rossby numbers are sufficiently small that we can approximate $q \approx f / h$ in the term $\overline{\hat{v}}_{\mathrm{Ek}} \hat{q}^{*}$, we find

$$
\begin{aligned}
\left(\bar{q}^{*}\right)^{-1}\left[-\bar{h} \overline{\hat{v}}_{\mathrm{Ek}} \hat{q}{ }^{*}+f \bar{v}_{\mathrm{Ek}}\right] \\
\quad=\left(\bar{q}^{*}\right)^{-1}\left[-\bar{h} \bar{v}_{\mathrm{Ek}} q^{*}+\bar{h} \bar{v}_{\mathrm{Ek}} * \bar{q}^{*}+f \bar{v}_{\mathrm{Ek}}\right] \\
\approx\left(\bar{q}^{*}\right)^{-1}\left[-f \bar{v}_{\mathrm{Ek}}+\bar{q}^{*} \overline{h v_{\mathrm{Ek}}}+f \bar{v}_{\mathrm{Ek}}\right] \\
\quad=\overline{h v_{\mathrm{Ek}}} .
\end{aligned}
$$



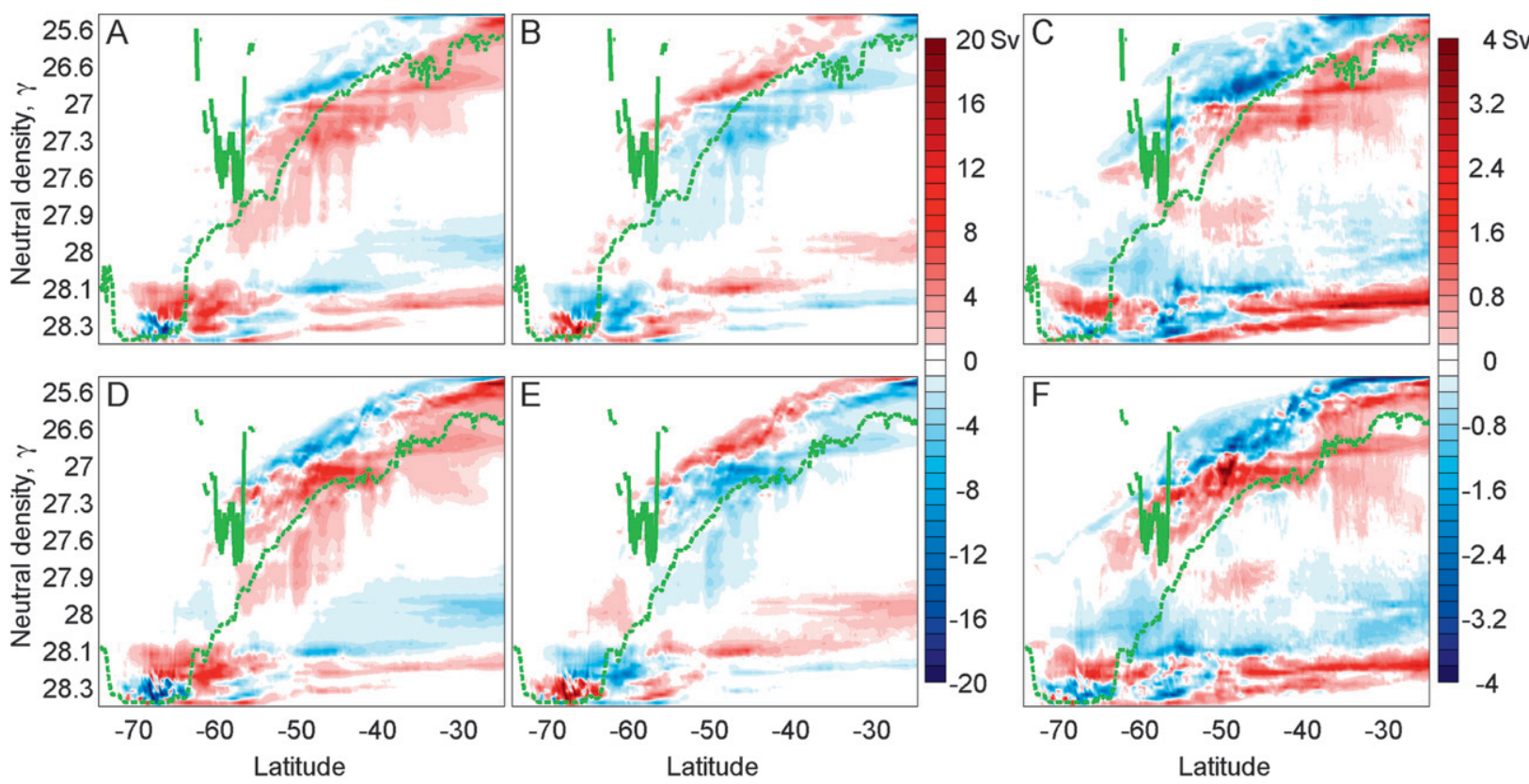

FIG. 8. Components of the meridional volume transport (Sv) associated with (a),(d) mean pressure gradients $\left(\bar{q}^{*}\right)^{-1} f \bar{v}_{g}=\left(\rho_{0} \bar{q}^{*}\right)^{-1} \overline{\mathcal{P}^{x}}$; (b),(e) transient geostrophic eddy potential vorticity fluxes $-\bar{h}\left(\bar{q}^{*}\right)^{-1} \overline{\tilde{v}}_{g} \tilde{q}^{*}$; and (c),(f) standing geostrophic eddy potential vorticity fluxes $-\bar{h}\left(\bar{q}^{*}\right)^{-1} \breve{v}_{g} \breve{q}^{*}$ in (top) austral summer and (bottom) austral winter. The standing geostrophic eddy flux is weak and thus is plotted with a different color bar.

Equation (16) confirms that the ageostrophic eddy fluxes and the temporally and zonally averaged Ekman velocity combine to approximate the total Ekman transport (Figs. 7c,f). When summed over all density classes, the total mechanical forcing does account for the roughly $30 \mathrm{~Sv}$ of equatorward SO Ekman transport (Mazloff et al. 2010).

\section{c. Mean geostrophic transport}

The mean geostrophic volume transport associated with the mean pressure gradient is given in (14) by $\left(\bar{q}^{*}\right)^{-1} f \bar{v}_{g}$. This transport carries the most buoyant waters poleward and slightly denser waters equatorward (Figs. 8a,d), thus implying a thermally direct upperocean overturning cell transporting buoyancy poleward. In addition, this transport carries the most dense waters equatorward, but slightly more buoyant waters poleward, implying a counterclockwise abyssal overturning cell. This pattern is apparent in all but the polar latitudes (south of $\sim 55^{\circ} \mathrm{S}$ ). In these latitudes, the mean geostrophic volume transport collapses into one thermally indirect cell, with the more buoyant waters moving equatorward and the densest waters moving poleward. Below the outcropping layers, the mean geostrophic volume transport is similar in magnitude in all seasons. In the outcropping layers, the mean geostrophic volume transport peaks in winter.
In these outcropping layers the relationships derived in section $2 \mathrm{~b}$ imply that the mean geostrophic volume transport is related to both standing and transient geostrophic eddy density fluxes at the ocean surface and bottom. For the surface layer in the unblocked latitudes we find that standing eddy density fluxes are typically a factor 5 stronger than transient eddy fluxes. Thus the surface layer mean geostrophic volume transport in this region is dominated by a time-mean standing eddy component.

\section{d. Geostrophic eddy transport}

We further decompose the geostrophic eddy potential vorticity flux into transient (tildes) and standing (carets) components,

$$
{\overline{\hat{v}_{g}}}^{*}{ }^{*}={\overline{\tilde{v}_{g}}}^{*}{ }^{*}+{\overline{\check{v}_{g}}}^{*}{ }^{*} .
$$

The calculation of these terms is accomplished by mapping the five-day-averaged SOSE velocity and potential vorticity to five-day-averaged $\gamma$, and then taking the time and zonal averages to compute the fluxes in $\gamma$ coordinates. Five-day averages are used because that is the frequency at which the SOSE output was saved; we do not expect the results to change if a higher frequency output were used. It is important to map properties onto $\gamma$ surfaces first, before averaging, so as not to underestimate eddy contributions. (This ordering of the 
calculation has not been consistently carried out in previous studies.)

After mapping to $\gamma$ surfaces, the transient and standing eddy fluxes are defined as

$$
\begin{aligned}
& \left.\overline{\tilde{A}}^{*}=\overline{(\overline{A B}}^{t^{*}-\bar{A}^{t^{*}} \bar{B}^{t^{*}}}\right)^{*}, \\
& \bar{A} \check{B}^{*}=\overline{\hat{A}}^{*}-\overline{\tilde{A}}^{*} \text {, }
\end{aligned}
$$

where $\overline{(\cdot)}^{t}$ and $\overline{(\cdot)}^{x}$ are the time and zonal mean, respectively, and as before asterisks denotes thickness weighting (e.g., $\bar{A}^{t^{*}}=\overline{A h}^{t} / \bar{h}^{t}$ ). We have also used the relation $\bar{A}^{*}={\overline{\left(\bar{A}^{t^{*}}\right.}}^{x^{*}}$.

In contrast to the surface fluxes in the unblocked latitudes, the transient geostrophic eddy PV flux is about an order of magnitude stronger than the standing eddy component. The volume transport associated with this transient flux, $-\bar{h}\left(\bar{q}^{*}\right)^{-1} \overline{\boldsymbol{v}}_{g} \tilde{q}^{*}$, counters the mean pressure gradient, with the most buoyant and deep waters both being driven equatorward and with intermediate and abyssal waters driven poleward (Figs. 8b,e). Like the other terms, its magnitude is largest in austral winter.

The volume transport associated with the standing geostrophic eddy PV flux, $-\bar{h}\left(\bar{q}^{*}\right)^{-1}{\overleftarrow{v_{g}}}^{*}{ }^{*}$, is weaker than that associated with the transient flux, but it is of the same order as the overall volume transport (Fig. 6). Geostrophic standing eddy PV fluxes primarily drive fluid equatorward (Figs. 8c,f), though in summer they drive a significant poleward transport of the most buoyant waters. Other exceptions are the poleward flux of abyssal waters in the polar gyres and of intermediate waters in the ACC latitudes.

\section{Synthesis of the MOC force balance}

Equation (14) showed that the momentum budget can be used to decompose the meridional volume flux into three dominant components: an eddy PV flux, an Ekman flux, and a geostrophic flux. In light of the discussions in the previous section, it is more convenient to regroup the terms as,

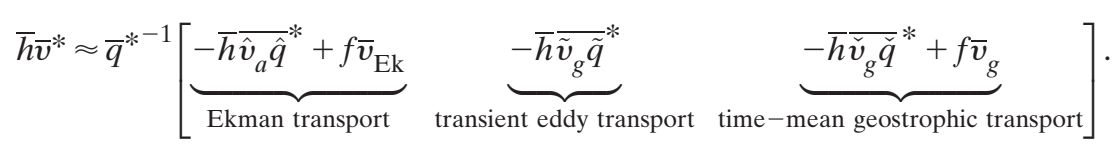

It may seem arbitrary to combine the standing eddy PV flux together with the mean geostrophic transport because at outcropping layers this mean term can include a transient eddy buoyancy flux (section $2 b$ ). As we discussed, however, most of the eddy buoyancy flux at outcrops is due to standing meanders, and hence this term primarily represents a transport owing to the timemean component of the flow. In this section we describe the relative importance of each component in contributing to the Southern Ocean MOC. We highlight dynamical differences and similarities between the polar gyre region, the ACC latitudes, and the subtropical gyre region.

\section{a. Subtropical and polar gyres}

The subtropical gyre regime extends from the northern edge of the domain to $\sim 40^{\circ} \mathrm{S}$ where the upper overturning cell ends (Fig. 2) approximately in correspondence with the subtropical front. There are three overturning cells in the subtropical gyre region, and in all of them the mean geostrophic volume flux dominates the circulation. In addition, there is a strong mechanically forced convergence of the most buoyant waters. Transient eddy PV fluxes are significant. They partially compensate the mean geostrophic transport and, thus, they reduce the strength of the overturning circulation that would exist without them. The dynamical balance of the subtropical upper overturning cell that emerges from this analysis is consistent with Sverdrup theory. The mean pressure gradients drive the interior flow equatorward, in accordance with vorticity conservation, while geostrophic western boundary currents and surface wind-driven flows close the mass and momentum budgets.

Mechanical forcing is weak poleward of Drake Passage in the Ross and Weddell Polar Gyres. The overturning in these latitudes consists primarily of the SO abyssal cell, though at these latitudes the "abyssal cell" spans all depths. With the exception of the weaker winddriven flow, the balance in this region is much like in the subtropical gyre, consisting of a mean geostrophic volume transport with significant compensation by transient eddies.

\section{b. ACC and Drake Passage latitudes}

Strong winds drive surface waters equatorward in the subpolar ACC region. With the exception of the dominance of this forcing on the most buoyant waters, the circulation in this region is balanced in the same way as in the polar and subtropical regions: a mean geostrophic mass transport is partially compensated by transient eddy PV fluxes. Comparing Fig. 6 with Figs. 8a,d shows 

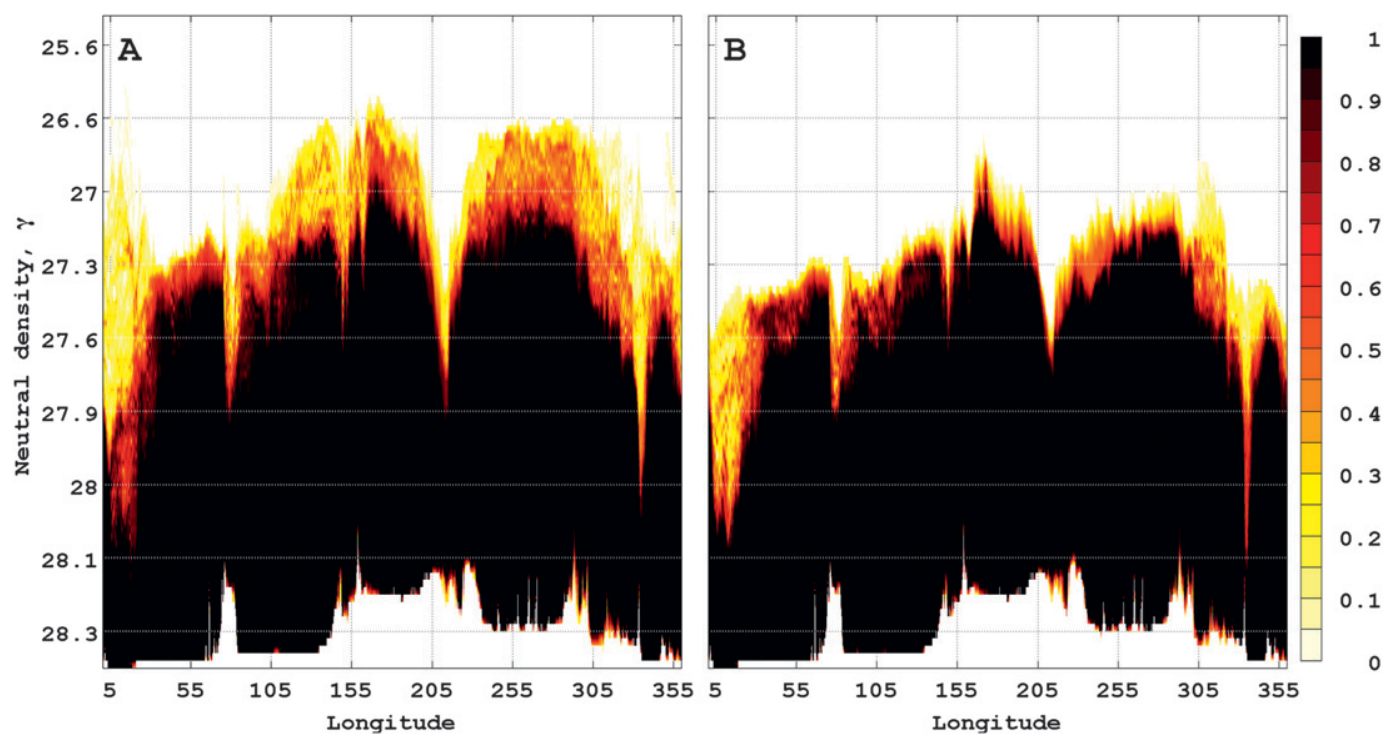

FIG. 9. Probability that an isopycnal layer exists in the Southern Ocean state estimate at $58^{\circ} \mathrm{S}$ in (a) summer and (b) winter. A value of one means that for the given location and season, the isopycnal layer is present at all times.

that the overturning structure below the mechanically forced layer is primarily a mean geostrophic transport.

There is a gap in the continental boundaries between $\sim 65^{\circ} \mathrm{S}$ and $\sim 55^{\circ} \mathrm{S}$, yet the dynamical balance in this Drake Passage region is similar to that of the northern ACC latitudes, which reach to about $\sim 40^{\circ} \mathrm{S}$. In particular, the zonal pressure gradient averaged along isopycnals does not vanish (Figs. 8a,d) because isopycnal surfaces are blocked along these latitude circles, and thus the zonally averaged zonal pressure gradient is nonzero. The isopycnal surfaces either run into bathymetry, predominantly at the Macquarie Ridge and the Kerguelen Plateau, or they outcrop at the surface, predominantly in the Weddell Sea (Fig. 9). It has become common in theorizing about the ACC (e.g., Olbers et al. 2004) to call pressure gradients against topography bottom form drag, and analogously we call pressure gradients resulting from surface outcrops surface form drag.

When zonally integrated at constant depth, the zonal pressure gradient vanishes by periodicity in Drake Passage. However, when integrating along neutral density surfaces, significant mean geostrophic flows can occur supported by surface form drag. A neutral density zonal section at $58^{\circ} \mathrm{S}$ shows there is a large-scale equatorward geostrophic transport of relatively buoyant waters in the south Indian and Pacific regions above the sill depth (Fig. 10). In the South Atlantic region, there is a poleward flow of relatively dense water at these same depths. These flows compensate such that the zonally integrated geostrophic volume transport at a fixed depth is negligible. However, a mean geostrophic volume transport exists when averaged along a density surface that outcrops, and thus an overturning circulation occurs in density coordinates, even in the unblocked latitudes. This is analogous to the overturning in the subtropical gyres resulting from the basin interior transport occurring at a different density than the western boundary current return flow. In the ACC, this phenomenon occurs at all length scales (note the wiggles in the mean density and sea surface height contours in Fig. 11). While this effect may be subtle, especially for small-scale meanders, it sums to a significant effect in the zonal integral.

We have found that standing meanders in the presence of isopycnal outcrops result in the mean geostrophic transport being a major contribution to the MOC in the ACC latitude band. This is different from the force balance diagnosed in idealized channel models (e.g., Abernathey et al. 2011) and often assumed in theorizing about the ACC (e.g., Marshall and Radko 2003). Typically a balance is expected between the Ekman volume fluxes and those associated with the transient eddy PV fluxes, with a minor contribution from surface geostrophic buoyancy fluxes (e.g., Marshall and Radko 2003). Instead, we find that the Ekman volume flux has the same sign as that associated with the transient eddy PV fluxes, and both are opposed by the mean geostrophic volume transport. However, the fact that this geostrophic transport in the ACC latitude band is largely due to standing meanders associated with density outcrops makes this discrepancy less puzzling. It is indeed eddies that balance the Ekman volume flux, but primarily standing rather than transient eddies and through their transport of surface buoyancy rather than PV. 


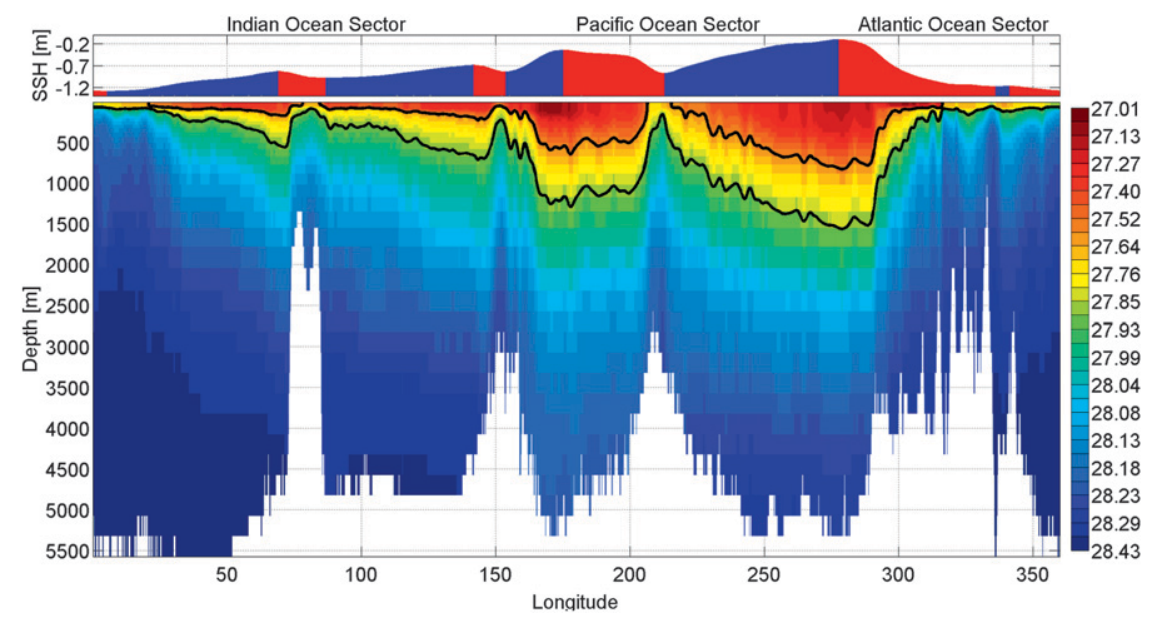

FIG. 10. (top) Longitudinal plot of smoothed mean sea surface height ( $\mathrm{SSH}$ ) at $58^{\circ} \mathrm{S}$, with blue implying poleward surface geostrophic flow (positive gradient) and red implying equatorward flow (negative gradient). Neutral density $\gamma$ averaged in winter at latitude $58^{\circ} \mathrm{S}$. The SSH suggests that near-surface poleward flow is often associated with less dense waters. Similarly, the MOC (Fig. 1) shows that fluid with $\gamma>27.6 \mathrm{~kg} \mathrm{~m}^{-3}$ (above the upper black contour) moves equatorward, while fluid with $\gamma<27.9 \mathrm{~kg} \mathrm{~m}^{-3}$ (below the lower black contour) moves poleward. These flows are largely geostrophic and occur at depths above the highest topography. The mean geostrophic volume transport vanishes when integrated at constant depth, but not when integrated at constant density.

It is possible that some of the differences between our results and previous work are due to the fact that we take averages along latitude circles rather than along streamlines. Starting with Marshall et al. (1993), it has been argued that the decomposition of the mean and eddy contributions to the Southern Ocean overturning is better achieved by averaging along the mean transport streamlines to follow the ACC standing meanders, rather than taking zonal averages. We found that rotating the momentum equations into along- and across-stream directions does not result in a significant reduction of the mean geostrophic transport. Apparently the structure of the ACC departs from equivalent barotropic, at least where there are significant standing meanders, to an extent that it is impossible to find "mean streamlines" that remove the geostrophic transport at all depths. Furthermore, the ACC meanders are very sharp in the SOSE solution and cumbersome curvature terms

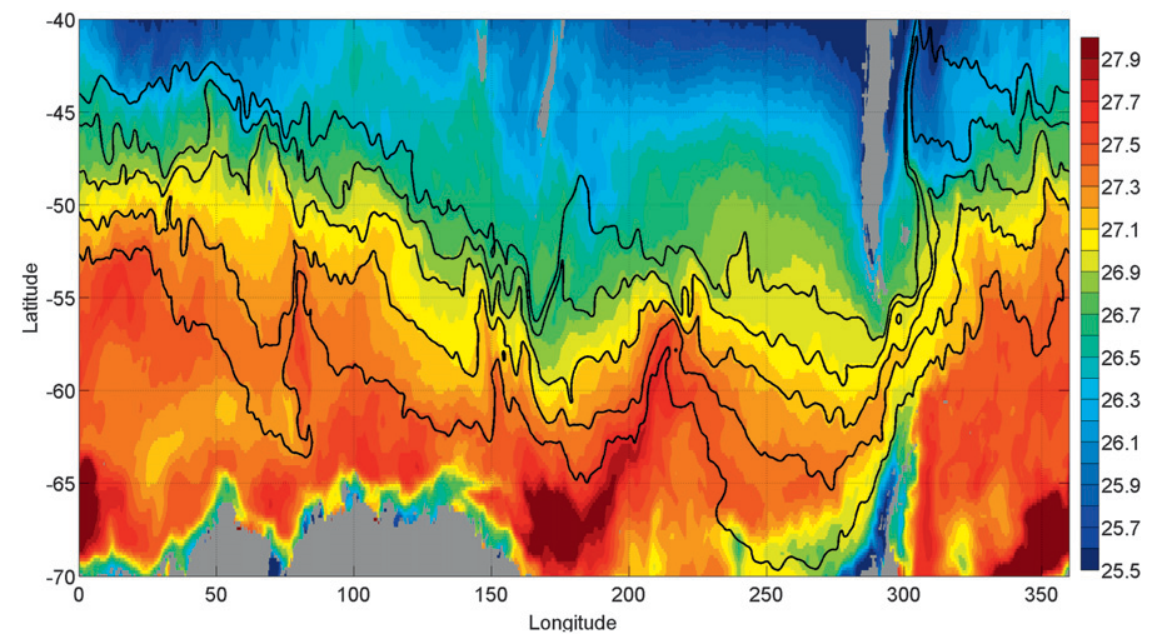

FIG. 11. Mean sea surface height contours plotted on top of mean surface neutral density. The surface geostrophic flow of the ACC does not follow density contours. Thus, across-streamline geostrophic buoyancy transport can be significant even if the geostrophic volume transport vanishes (i.e., though $\oint v_{g} d s$ may vanish, $\oint v_{g} \gamma d s$ is likely to be finite). 


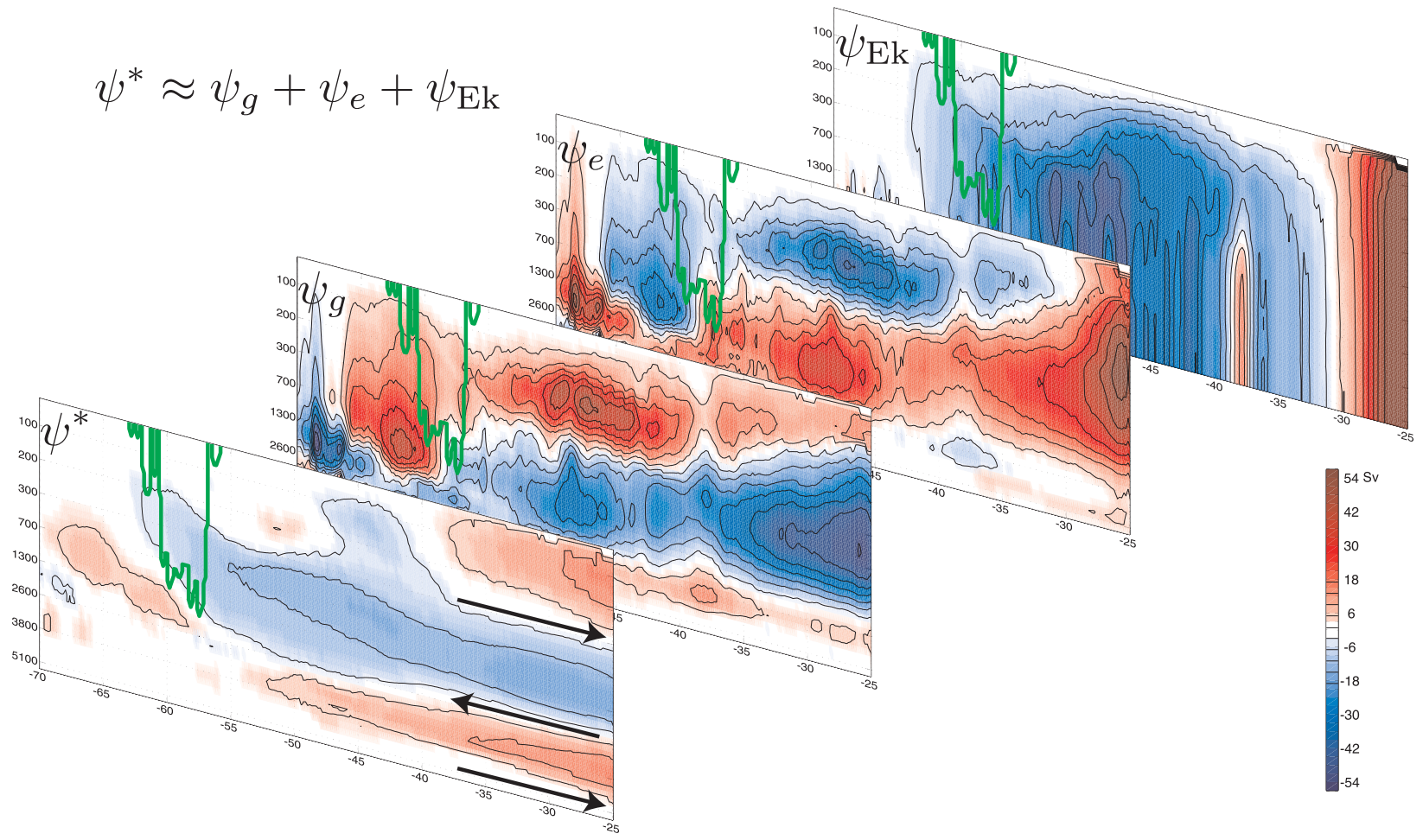

FIG. 12. The two-year mean meridional overturning circulation, $\psi^{*}=\rho_{0}^{-1} \int \bar{h} \bar{v}^{*} d \gamma$, mapped to mean isopycnal depths is decomposed into the mean geostrophic flux $\psi_{g} \equiv \rho_{0}^{-1} \int\left(\bar{q}^{*}\right)^{-1} f \bar{v}_{g} \mathrm{~d} \gamma$, the transient eddy potential vorticity flux $\psi_{e}=-\rho_{0}^{-1} \int \bar{h}\left(\bar{q}^{*}\right)^{-1} \overline{\boldsymbol{v}}_{g} \tilde{q}^{*} d \gamma$, and the Ekman flux $\psi_{\text {Ek }} \equiv \rho_{0}^{-1} \int \overline{h v_{\text {Ek }}} \mathrm{d} \gamma$.

would need to be included in the momentum equations if one insists on following them accurately.

\section{Summary and conclusions}

We analyzed the Southern Ocean limb of the meridional overturning circulation using an eddy-permitting state estimate run for the years 2005 and 2006. The circulation was diagnosed as a function of neutral density, a natural coordinate system for the ocean where motions flow along these surfaces outside boundary layers. We found that the global overturning $\psi^{*}=\rho_{0}^{-1} \int \bar{h} \bar{v}^{*} \mathrm{~d} \gamma$ is best thought as the sum of three components: a winddriven transport $\psi_{\text {Ek }} \equiv \rho_{0}^{-1} \int \overline{h v_{\text {Ek }}} \mathrm{d} \gamma$, a mean geostrophic transport $\psi_{g} \equiv \rho_{0}^{-1} \int\left(\bar{q}^{*}\right)^{-1} f \bar{v}_{g} \mathrm{~d} \gamma$, and a transport associated with a transient eddy flux of potential vorticity $\psi_{e} \equiv-\rho_{0}^{-1} \int \bar{h}\left(\bar{q}^{*}\right)^{-1} \tilde{\boldsymbol{v}}_{g} \tilde{q}^{*} \mathrm{~d} \gamma$. The decomposition is shown in Fig. 12, where the results are mapped back into the more familiar $z$ coordinates. (The transport value on each isopycnal is mapped to the zonal mean depth of that isopycnal and then integrated to determine the streamfunction.)

The wind-driven transport $\psi_{\mathrm{Ek}}$ is significant at all latitudes near the surface. In the ACC latitude band, it is responsible for a sizable equatorward transport of buoyant waters. The mean geostrophic transport $\psi_{g}$ is supported by mean zonal pressure gradients that arise from isopycnal outcrops into either bottom topography or the surface. In the Drake passage latitude band, the primary blockage in isopycnal coordinates comes from bottom outcrops at the Kerguelan Plateau $\left(\sim 70^{\circ} \mathrm{E}\right)$ and Macquarie Ridge $\left(\sim 160^{\circ} \mathrm{E}\right)$ and surface outcrops in the eastern Weddell Sea $\left(\sim 0^{\circ}\right)$. The Campbell Plateau at $155^{\circ} \mathrm{E}$ and the Pacific-Antarctic Ridge to its east are also notable constriction points. The surface outcrops span many more neutral density classes than do the bottom outcrops (Fig. 9).

The transport associated with transient eddy PV fluxes $\psi_{e}$ has the same pattern and opposite sign of the mean geostrophic transport at most latitudes and depths (Figs. 8 and 12). The transient eddy PV fluxes are, for the most part, oriented down the mean PV gradient along isopycnals. In $z$ coordinates, one primarily focuses on the PV gradients between the well-stratified pycnocline and the thick isopycnal layers in the interior. The interior PV generally decreases southward, and we do find a southward transient eddy PV flux, which is associated with poleward volume transport (Figs. 8b,e). Isopycnal coordinates also make manifest the contribution of the surface layer where isopycnals outcrop. There, $\mathrm{PV}$, with the averaging convention we adopted, generally 
decreases northward. Correspondingly, the eddy PV flux is directed northward and is associated with equatorward volume transport. The isopycnal analysis shows that, by transporting volume toward the pycnocline (equatorward along isopycnals), the transient eddy PV fluxes and Ekman transport together tend to oppose the mean geostrophic transport.

The transport balance that we diagnose in the ACC latitude band differs from the prevailing view, which posits that the Ekman transport is opposed by a transient eddy transport associated with adiabatic PV fluxes (e.g., Johnson and Bryden 1989; Olbers et al. 2004). However, the two balances are not as different upon closer inspection. In both cases there is a balance between an Ekman transport and an eddy transport, but in our analysis the eddy transport is dominated by horizontal diabatic geostrophic buoyancy fluxes at the surface rather than by adiabatic PV fluxes. The isopycnal averaging used in this paper, as opposed to the averaging at fixed $z$ used in previous analyses of the momentum budget, shows that upon circumpolar integration almost all isopycnals pass through a surface or bottom boundary layer at some point in the seasonal average (Fig. 9). One expects diabatic processes to be influential in these boundary layers, and thus it is not surprising that diabatic fluxes dominate the transport. Indeed, a large geostrophic flow across density outcrops has been previously identified in a suite of idealized studies (e.g., Treguier et al. 1997; Marshall and Radko 2003; Kuo et al. 2005) and has been shown to have observable consequences for watermass transport and subduction (Sallée et al. 2010). Our analysis suggests that this mechanism is responsible for a large fraction of the total volume transport in the ACC region.

Consistent with previous model diagnoses (Stevens and Ivchenko 1997; Lee and Coward 2003; Dufour et al. 2012), we have found that standing eddy transports play a significant role in the Southern Ocean MOC. The geostrophic buoyancy flux across a latitude circle is achieved by transporting negative buoyancy anomalies when the ACC veers north and positive ones when it veers south. Significant meanders can be seen in the lee of major topographic features, but there are also many smaller ones. The dominance of standing eddies raises a challenge for parameterizations of eddy transport in the ACC. Transient eddy fluxes of buoyancy can be parameterized as a downgradient buoyancy flux (Treguier et al. 1997), while standing eddies are supported by seasonalmean outcrops and there is no guiding principle for their parameterization.

Our analysis shows that isopycnal outcropping allows mean pressure gradients to oppose the Ekman transport in the ACC latitudes. If the equatorward Ekman transport (i.e., the zonal wind stress) increases, it is likely that more deep water will be brought to the surface, resulting in more outcrops, which will then be able to support a stronger mean geostrophic circulation. This balance is, to some degree, observable. In winter when the mean zonal wind stress is greatest (Fig. 7c), zonal outcropping is most significant (Fig. 9b), and the mean geostrophic transport is strongest (Fig. 7d). More outcroppings also result in more significant air-sea gas exchange, with implications for biogeochemical climate predictions.

Acknowledgments. We acknowledge the National Science Foundation (NSF) for support of this research through Grants OCE-1233832, OCE-1234473, and OPP0961218. SOSE was produced using the Extreme Science and Engineering Discovery Environment (XSEDE), which is supported by National Science Foundation Grant MCA06N007.

\section{REFERENCES}

Abernathey, R., J. Marshall, and D. Ferreira, 2011: The dependence of Southern Ocean meridional overturning on wind stress. J. Phys. Oceanogr., 41, 2261-2278.

Andrews, D. G., 1983: A finite-amplitude Eliassen-Palm theorem in isentropic coordinates. J. Atmos. Sci., 40, 1877-1883.

- and M. E. McIntyre, 1976: Planetary waves in horizontal and vertical shear: The generalized Eliassen-Palm relation and the mean zonal acceleration. J. Atmos. Sci., 33, 2031-2048.

, J. Holton, and C. Leovy, 1987: Middle Atmosphere Dynamics. Academic Press, 489 pp.

Dufour, C. O., J. Le Sommer, J. D. Zika, M. Gehlen, J. C. Orr, P. Mathiot, and B. Barnier, 2012: Standing and transient eddies in the response of the Southern Ocean meridional overturning to the southern annular mode. J. Climate, 25, 6958-6974.

Gill, A., 1968: A linear model of the Antarctic Circumpolar Current. J. Fluid Mech., 32, 465-488.

Held, I. M., and T. Schneider, 1999: The surface branch of the mass transport circulation in the troposphere. J. Atmos. Sci., 56, $1688-1697$.

Jackett, D. R., and T. J. McDougall, 1997: A neutral density variable for the world's oceans. J. Phys. Oceanogr., 27, 237-263.

Johnson, G. C., and H. L. Bryden, 1989: On the size of the Antarctic Circumpolar Current. Deep-Sea Res., 36, 39-53.

Juckes, M. N., I. N. James, and M. Blackburn, 1994: The influence of Antarctica on the momentum budget of the southern extratropics. Quart. J. Roy. Meteor. Soc., 120, 1017-1044.

Koh, T.-Y., and R. A. Plumb, 2004: Isentropic zonal average formalism and the near-surface circulation. Quart. J. Roy. Meteor. Soc., 130, 1631-1653.

Kuo, A., R. A. Plumb, and J. Marshall, 2005: Transformed Eulerianmean theory. Part II: Potential vorticity homogenization and the equilibrium of a wind- and buoyancy-driven zonal flow. J. Phys. Oceanogr., 35, 175-187.

LaCasce, J., and P. Isachsen, 2010: The linear models of the ACC. Prog. Oceanogr., 84 (3-4), 139-157.

Lee, M.-M., and A. Coward, 2003: Eddy mass transport for the Southern Ocean in an eddy-permitting global ocean model. Ocean Modell., 5, 249-266. 
Marshall, J., and T. Radko, 2003: Residual-mean solutions for the Antarctic Circumpolar Current and its associated overturning circulation. J. Phys. Oceanogr., 33, 2341-2354.

—, D. Olbers, H. Ross, and D. Wolfgladrow, 1993: Potential vorticity constraints on the dynamics and hydrography of the Southern Ocean. J. Phys. Oceanogr., 23, 465-487.

Mazloff, M., 2008: The dynamics of the Southern Ocean meridional overturning circulation as diagnosed from an eddy permitting state estimate. Ph.D. thesis, Massachusetts Institute of Technology and the Woods Hole Oceanographic Institution, $127 \mathrm{pp}$.

— , P. Heimbach, and C. Wunsch, 2010: An eddy-permitting Southern Ocean state estimate. J. Phys. Oceanogr., 40, 880-899.

McDougall, T. J., and P. C. McIntosh, 1996: The temporal-residualmean velocity. Part I: Derivation and the scalar conservation equations. J. Phys. Oceanogr., 26, 2653-2665.

McIntosh, P. C., and T. J. McDougall, 1996: Isopycnal averaging and the residual mean circulation. J. Phys. Oceanogr., 26, 1655-1660.

Nadeau, L.-P., and D. N. Straub, 2009: Basin and channel contributions to a model Anarctic Circumpolar Current. J. Phys. Oceanogr., 39, 986-1002.

- , and -2012 : Influence of wind stress, wind stress curl, and bottom friction on the transport of a model Antarctic Circumpolar Current. J. Phys. Oceanogr., 42, 207-222.

Nikurashin, M., and G. Vallis, 2011: A theory of deep stratification and overturning circulation in the ocean. J. Phys. Oceanogr., 41, 485-502.

— and - 2012: A theory of the interhemispheric meridional overturning circulation and associated stratification. J. Phys. Oceanogr., 42, 1652-1667.

Nurser, A. J. G., and M.-M. Lee, 2004: Isopycnal averaging at constant height. Part II: Relating to the residual streamfunction in Eulerian space. J. Phys. Oceanogr., 34, 2740-2755.

Olbers, D., D. Borowski, C. Volker, and J.-O. Wolff, 2004: The dynamical balance, transport and circulation of the Antarctic Circumpolar Current. Antarct. Sci., 16, 439-470.
Pedlosky, J., 1987: Geophysical Fluid Dynamics. 2nd ed. SpringerVerlag, $710 \mathrm{pp}$.

Phillips, N. A., 1963: Geostrophic motion. Rev. Geophys., 1, $123-$ 176.

Plumb, R. A., and R. Ferrari, 2005: Transformed Eulerian-mean theory. Part I: Nonquasigeostrophic theory for eddies on a zonal-mean flow. J. Phys. Oceanogr., 35, 165-174.

Robinson, A., and H. Stommel, 1959: The oceanic thermocline and the associated thermohaline circulation. Tellus, 11, 295-308.

Sallée, J.-B., K. Speer, S. Rintoul, and S. Wijffels, 2010: Southern Ocean thermocline ventilation. J. Phys. Oceanogr., 40, 509-529.

Samelson, R. M., 1999: Geostrophic circulation in a rectangular basin with a circumpolar connection. J. Phys. Oceanogr., 29, 3175-3184.

Schneider, T., 2005: Zonal momentum balance, potential vorticity dynamics, and mass fluxes on near-surface isentropes. $J$. Atmos. Sci., 62, 1884-1900.

— I. M. Held, and S. T. Garner, 2003: Boundary effects in potential vorticity dynamics. J. Atmos. Sci., 60, 1024-1040.

Stevens, D. P., and V. O. Ivchenko, 1997: The zonal momentum balance in an eddy-resolving general-circulation model of the Southern Ocean. Quart. J. Roy. Meteor. Soc., 123, 929-951.

Treguier, A. M., I. M. Held, and V. D. Larichev, 1997: Parameterization of quasigeostrophic eddies in primitive equation ocean models. J. Phys. Oceanogr., 27, 567-580.

Vallis, G. K., 2006: Atmospheric and Oceanic Fluid Dynamics. Cambridge University Press, 745 pp.

Welander, P., 1959: An advective model of the ocean thermocline. Tellus, 11, 309-318.

Wunsch, C., and P. Heimbach, 2009: The global zonally integrated ocean circulation, 1992-2006: Seasonal and decadal variability. J. Phys. Oceanogr., 39, 351-368.

Wüst, G., 1935: Zur Frage des indischen Tiefenstroms. Naturwissenschaften, 23,137-139. (In English, 1978: The Stratosphere of the Atlantic Ocean. W. J. Emery, Ed., Amerind, 112 pp.) 